\title{
Time to treatment of prostate cancer patients
}

\author{
Monika Rucińska', Karolina Osowiecka ${ }^{2}$, Szymon Gałka ${ }^{3}$, Radosław Środa ${ }^{3}$, \\ Piotr Wojciechowski ${ }^{3}$, Anna Sugajska ${ }^{1}$
}

'Department of Oncology, University of Warmia and Mazury in Olsztyn

Head of Department: Monika Rucińska

2 Department of Public Health, Epidemiology and Microbiology,

University of Warmia and Mazury in Olsztyn

Head of Department: Joanna Białkowska

${ }^{3}$ Student Scientific Society of the Department of Oncology,

University of Warmia and Mazury in Olsztyn

\section{Correspondence: \\ Monika Rucińska Department of Oncology, University of Warmia and \\ Mazury in Olsztyn \\ 10-228 Olsztyn, al. Wojska Polskiego 37 \\ e-mail:m_rucinska@ poczta.onet.pl \\ Received: 8.04.2018 \\ Accepted: \\ 8.08.2018}

DOI: 10.24292/01.OR.080818 Copyright $\odot$ Medical Education. All rights reserved.

\section{ABSTRACT}

Prostate cancer is one of the most common cancers in men. The incidence of prostate cancer increases systematically. The correlation between waiting time for oncological treatment and survival prognosis in prostate cancer is not clearly determined.

The aim of the study was to estimate the waiting time from suspicion until prostate cancer diagnosis and treatment in Warmia and Mazury Voivodeship.

Ninety-six consecutive prostate cancer patients treated with radical radiotherapy between November 2016 and June 2017 in the Department of Radiation Oncology of the Hospital of the Ministry of Internal Affairs with Warmia and Mazury Oncology Center in Olsztyn were included in the analysis. A questionnaire prepared especially for this study, and individual interviews with patients were used in the study. The obtained data was supplemented with medical records and hospital databases. In the case of twenty-nine men, the PSA concentration was measured due to urinary disorders, and the median time from symptoms until the first PSA test in that group was 168 days. The median time from PSA concentration $>4 \mathrm{ng} / \mathrm{ml}$ to biopsy of prostate cancer and start of treatment for all patients was 62 and 156 days, respectively. Hormone therapy was administered the quickest. A positive correlation was observed between the waiting time from histopathological confirmation of prostate cancer until treatment, and the distance from one's place of residence to the oncological center $(p<0.05)$.

Key words: prostate cancer, waiting for treatment 


\section{INTRODUCTION}

Prostate cancer is one of the most common neoplastic diseases. It ranks second across the world in terms of incidence, and it ranks fifth in terms of cancer deaths in men [1]. The situation is similar in Poland, with prostate cancer being second only to lung cancer, when it comes to incidence in male patients, constituting $17 \%$ of new malignant cases in men. Over 12 thousand men are diagnosed with prostate cancer in Poland each year [2].

Prostate cancer incidence increases systematically. In part, it is likely linked to an ever greater availability and popularity of prostate-specific antigen (PSA) testing [3]. It makes it possible to detect asymptomatic cases of prostate cancer, often at an early stage of development. Presently, we might even refer to the phenomenon of over-diagnosis and over-treatment, as the malignancy is frequently diagnosed and treated in men, in whom it might never progress to a health- or life-threatening stage [4] On the other hand, it is important to be able to diagnose high-grade prostate cancer early enough, especially in younger men, without delaying treatment. Advanced prostate cancer becomes an incurable disease, and it may constitute the patient's cause of death. Around 4800 men die of that cause in Poland each year, with the 5-year survival rate amounting to $76.4 \%$ [2].

Measuring PSA levels, especially in the high-risk group of patients (males over the age of 60 with a positive family history of prostate cancer) may contribute to detecting the disease at a sufficiently early stage, thus enabling radical treatment. However, there is no evidence that the PSA test may be used as a screening test in prostate cancer, as the impact of PSA testing on reduced prostate cancer mortality rates has not been proven so far [5].

The correlation between time to oncological treatment and prognosis has not been clearly defined for prostate cancer patients [6]. At an early stage of the disease, watchful waiting is a possible course of management, without initiating anti-cancer treatment, and offering it only in the case of disease progression [7]. According to several analyses, delaying a radical surgery, even up to a year from diagnosis, does not have a negative impact on prognosis [7-9]. One of the studies even went as far as to indicate that patients who had undergone prostatectomy within the shortest possible time from diagnosis lived shorter than those whose surgery was delayed [10]. The apparent delay of radical radiation treatment often involves the administration of a 6-month-long neo-adjuvant hormone therapy. On the other hand, if hormone therapy is not applied, and time to radiation is delayed by more than 6 months, biochemical progression is more frequent [11]. Nguyen et al. indicated that the 5 -year survival without PSA pro- gression depends on the delayed time to radiotherapy only in the high-risk group of patients [12]. On the other hand, Andrews et al. observed no impact of delaying radiotherapy, even by 9 months, on biochemical progression or overall survival, which also applied to the high-risk patients [13].

What remains of significance is also the stress and anxiety experienced by patients awaiting treatment [14]. Studies indicate that for many patients the most difficult time is that of waiting for the initiation of therapy [15], with prolonged waiting times potentially lowering the patients' quality of life [16]. A retrospective assessment of anxiety levels among male patients, depending on the treatment selected, indicated that it was the highest in patients qualified for watchful waiting $[15,17]$.

\section{AIMS OF THE STUDY}

The present study was aimed at determining the time that patients with a suspicion of prostate cancer had to wait for diagnosis and initiation of treatment in the Warmia and Mazury province, and at estimating the impact of different factors on the waiting time involved.

\section{MATERIAL AND METHODS}

The study involved a number of consecutive patients who presented with a histopathological confirmation of prostate cancer at the Radiotherapy Clinic within the Independent Public Health Care Facility of the Ministry of Internal Affairs and Administration with Warmia and Mazury Oncology Center in Olsztyn in the period from November 2016 through June 2017, and were qualified for radical radiotherapy treatment.

The study made use of a questionnaire, prepared especially for the purpose of this analysis, and a detailed patient interview. The data was additionally supplemented with information derived from the patients' medical records. The questionnaire had previously been validated in a group of 50 subjects. Inter-rater agreement was measured with Cohen's kappa coefficient.

The study was approved by the Bioethics Committee affiliated with the University of Warmia and Mazury in Olsztyn. Participation in the study was voluntary. All respondents expressed their written consent to participate in the study, also consenting to their medical records being analyzed.

Median waiting times, from prostate cancer suspicion to diagnosis, and from diagnosis to treatment, were estimated. The time of 
prostate cancer suspicion was considered as the date on which the first clinical symptoms suggestive of prostate cancer were reported or the date of PSA serum levels exceeding $4 \mathrm{ng} / \mathrm{ml}$. The date of diagnosis was assumed to be the date of histological confirmation of the disease (date of completed examination or date of result printout). The duration of histopathology examination was measured from the date of material collection to the date of examination completion and/or result printout. The following times were measured: from the onset date of the first symptoms to the date of the first PSA test, from the onset date of the first symptoms to the date of PSA $>4 \mathrm{ng} / \mathrm{ml}$, from the date of the first PSA test result $>4 \mathrm{ng} / \mathrm{ml}$ to the date of prostate biopsy, from the date of the prostate biopsy procedure to the date of the biopsy result, from the onset date of the first symptoms to the date of treatment initiation, from the date of the first PSA test result $>4 \mathrm{ng} / \mathrm{ml}$ to the start of anti-cancer therapy, and from the date of histological confirmation to the start of anti-cancer therapy.

Median waiting times were estimated with respect to the execution of the above mentioned stages of the diagnostic process. Due to the non-normal distribution of the waiting time variables ( $p<0.05)$, as analyzed with the Shapiro-Wilk test, non-parametric tests were used for data analysis. The Mann-Whitney and Kruskal-Wallis tests were applied to explore the differences in waiting times between the different study groups. Spearman's rank correlation coefficient was used to examine the correlation between the distance to the oncology center in Olsztyn and the consecutive stages of the diagnostic process ( $r$ - correlation coefficient). The level of statistical significance was defined as $p<0.05$. Statistical analyses were performed with the use of the STATISTICA software (version 13; StatSoft, Poland) and SPSS 23.0.

\section{RESULTS}

The study included 96 consecutive patients who presented with prostate cancer diagnosis at the Radiotherapy Clinic within the Independent Public Health Care Facility of the Ministry of Internal Affairs and Administration with Warmia and Mazury Oncology Center in Olsztyn in the period from November 2016 through June 2017, and were qualified for radical radiotherapy. The studied male subjects were aged 46-92 (median age: 71). 21 patients (21.9\%) lived in Olsztyn, 55 (57.3\%) were residents of smaller towns, and 20 (20.8\%) lived in the countryside.

All patients had received a histopathological diagnosis of prostate cancer (adenocarcinoma prostate). Their Gleason score ranged from 5 to 10 (median of 7). Baseline serum PSA levels (considered elevated) were $4.00-93.76 \mathrm{ng} / \mathrm{ml}$ (median: $9.89 \mathrm{ng} / \mathrm{ml}$ ). In half of the patients (50\%), the PSA concentration that triggered further diagnostics was lower than $10 \mathrm{ng} / \mathrm{ml}$, and in nearly one fifth of the patients (18.7\%), the baseline PSA level was above $20 \mathrm{ng} / \mathrm{ml}$. In all study subjects, adequate clinical and imaging diagnostics was carried out, based on which disease clinical advancement was determined as T1-T4NOM0. Most of the patients, i.e. 71 of them $(74 \%)$, were diagnosed with T2NOM0 prostate cancer. There were 15 patients ( $15.6 \%$ of the studied population) whose risk of progression was low, 35 men (36.5\%) had an intermediate risk of progression, 34 (35.4\%) of them were included in the high-risk group, and $8(8.3 \%)$ patients were considered to have a very high risk of progression according to NCCN 2017 guidelines (tab. 1.).

TABLE 1.

Study group characteristics.

\begin{tabular}{|c|c|c|}
\hline & $\mathbf{N}$ & $\%$ \\
\hline & 96 & 100 \\
\hline \multicolumn{3}{|c|}{ Age (years): 46-92; median: 71} \\
\hline \multicolumn{3}{|c|}{$\begin{array}{l}\begin{array}{l}\text { Aggressiveness of prostate cancer based on Gleason score: } 5-10 ; \\
\text { median: } 7\end{array} \\
\end{array}$} \\
\hline$<6$ & 2 & 2.1 \\
\hline $6-7$ & 67 & 69.8 \\
\hline$>7$ & 26 & 27.1 \\
\hline No data & 1 & 1.0 \\
\hline
\end{tabular}

Baseline serum PSA levels (ng/ml): 4-93.96; median: 9.89

\begin{tabular}{|c|c|c|}
\hline$<10$ & 48 & 50.0 \\
\hline $10-20$ & 28 & 29.2 \\
\hline$>20$ & 18 & 18.7 \\
\hline No data & 2 & 2.1 \\
\hline
\end{tabular}

Stage of clinical advancement according to the TNM staging system: T1-T4 NOMO

\begin{tabular}{|c|c|c|}
\hline T1 & 6 & 6.2 \\
\hline T2 & 71 & 74.0 \\
\hline T3 & 14 & 14.6 \\
\hline T4 & 1 & 1.0 \\
\hline No data & 4 & 4.2 \\
\hline
\end{tabular}

Risk of progression according to the NCCN(2017) guidelines

\begin{tabular}{|c|c|c|}
\hline Low & 15 & 15.6 \\
\hline Intermediate & 35 & 36.5 \\
\hline High & 34 & 35.4 \\
\hline Very high & 8 & 8.3 \\
\hline No data & 4 & 4.2 \\
\hline First treatment method \\
\hline Surgery & 7 & 7.3 \\
\hline Radiotherapy & 9 & 9.4 \\
\hline Hormone therapy & 80 & 83.3 \\
\hline \multicolumn{2}{|c|}{ Place of residence } \\
\hline Olsztyn & 21 & 21.9 \\
\hline Town < 100 thousand residents & 55 & 57.3 \\
\hline Countryside & 20 & 20.8 \\
\hline
\end{tabular}


Half of the patients (51\%) had had a PSA test done for no specific reason, upon their own initiative or having received a referral from their family physician, without any coexisting symptoms indicative of prostate cancer. In five patients (5.2\%), PSA levels were tested during their hospital stay for a different reason. 29 study subjects (30.2\%) underwent PSA testing due to urinary problems, with pollakiuria being the most common one reported. In the case of 13 patients (13.6\%), the reason behind the PSA test was difficult to establish. PSA test referrals were issued to patients by urology specialists (40 respondents, $41.7 \%$ ), family physicians (38 respondents, 39.6\%) or other specialists (6 patients, 6.2\%). 12 respondents $(12.5 \%)$ underwent a privately funded PSA test, without referral.

All study subjects were qualified for radical radiotherapy. Most of them (80 respondents, 83.3\%) started treatment from 6 months of hormone therapy, followed by radical radiotherapy. Nine patients (9.4\%) received radiotherapy without prior neoadjuvant hormone therapy. Seven men (7.3\%) underwent prostatectomy first, but required post-operative radiotherapy.

In 29 patients, PSA levels were tested due to urinary problems. In that group, median time from the onset of symptoms to the first PSA test was 168 days, and it was 216 days from the onset of symptoms to a PSA level exceeding $4 \mathrm{ng} / \mathrm{ml}$. Median time from the finding of an elevated PSA concentration ( $>4 \mathrm{ng} / \mathrm{ml}$ ) to prostate gland biopsy was 71 days for patients with urinary symptoms. On the other hand, for patients without urinary symptoms, median time from a PSA test result $>4 \mathrm{ng} / \mathrm{ml}$ to prostate gland biopsy was 56 days. For the entire studied population, median time from the finding of PSA $>4 \mathrm{ng} / \mathrm{ml}$ to prostate gland biopsy was 62 days (tab. 2).

Median waiting time from biopsy to histopathological diagnosis was 8 days (taking into account the date of signature or printout of the histological results, and not the date of collecting the results by the attending physician, or handing the results over to the patient).

Median time from receiving the histological results to the initiation of oncological treatment was 65 days for all patients (71 for symptomatic patients, and 59 for those without urinary symptoms). Median time from the finding of elevated PSA ( $>4 \mathrm{ng} / \mathrm{ml}$ ) to the initiation of treatment was 156 days for all study subjects. Patients with urinary symptoms received anti-cancer treatment as late as 490 days (median time) after the onset of symptoms. Hormone therapy was initiated the fastest, with the

TABLE 2.

Median waiting time for prostate gland biopsy and treatment in patients with or without urinary symptoms.

\begin{tabular}{|c|c|c|c|c|}
\hline & Waiting time & $\mathbf{N}$ & Median (days) & (lower-upper quartile) \\
\hline \multirow{5}{*}{$\begin{array}{l}\text { Patients with urinary } \\
\text { symptoms }\end{array}$} & from the onset of symptoms to the first PSA test & 26 & 168 & $(40-382)$ \\
\hline & from the onset of symptoms to PSA $>4 \mathrm{ng} / \mathrm{ml}$ & 26 & 216 & $(77-505)$ \\
\hline & from PSA > $4 \mathrm{ng} / \mathrm{ml}$ to prostate gland biopsy & 28 & 71 & $(20-219)$ \\
\hline & from histopathological diagnosis to the start of treatment & 26 & 71 & $(39-108)$ \\
\hline & from the onset of symptoms to the start of treatment & 26 & 490 & $(226-1182)$ \\
\hline \multirow{2}{*}{$\begin{array}{l}\text { Patients without } \\
\text { urinary symptoms }\end{array}$} & from PSA > $4 \mathrm{ng} / \mathrm{ml}$ to prostate gland biopsy & 66 & 56 & $(33-189)$ \\
\hline & from histopathological diagnosis to the start of treatment & 67 & 59 & $(35-98)$ \\
\hline \multirow{7}{*}{ All patients } & from PSA > $4 \mathrm{ng} / \mathrm{ml}$ to prostate gland biopsy & 94 & 62 & $(30-217)$ \\
\hline & from biopsy to histopathological diagnosis & 92 & 8 & $(7-11)$ \\
\hline & from histopathological diagnosis to the start of treatment & 93 & 65 & $(38-101)$ \\
\hline & $\begin{array}{l}\text { from histopathological diagnosis to the start of hormone } \\
\text { therapy }\end{array}$ & 77 & 53 & $(35-79)$ \\
\hline & from histopathological diagnosis to surgery & 7 & 91 & $(48-168)$ \\
\hline & $\begin{array}{l}\text { from histopathological diagnosis to the start of } \\
\text { radiotherapy alone }\end{array}$ & 9 & 169 & $(98-243)$ \\
\hline & from PSA $>4 \mathrm{ng} / \mathrm{ml}$ to the start of treatment for all patients & 95 & 156 & $(78-348)$ \\
\hline
\end{tabular}


median time of 53 days from receiving the histological results to the start of ADT therapy. Surgery was performed 91 days from the histological diagnosis (applicable to 7 patients, who later underwent post-operative radiotherapy) (fig. 1). Median time to radiotherapy alone was the longest, amounting to 169 days (within that period patients underwent a number of procedures in preparation for radiotherapy, e.g. all patients had MRI scans performed, they had intraprostatic markers implanted before radiation therapy, and had their treatment plan devised). A statistically significant difference was observed between the waiting time from diagnosis to the initiation of hormone therapy, and the time from diagnosis to radiotherapy alone $(p<0.001)($ tab. 3).

FIGURE 1.

The waiting time for diagnosis and treatment.

$\begin{array}{lll}\text { Symptoms } & \text { First PSA test Treatment }\end{array}$

PATIENTS WITH URINARY SYMPTOMS

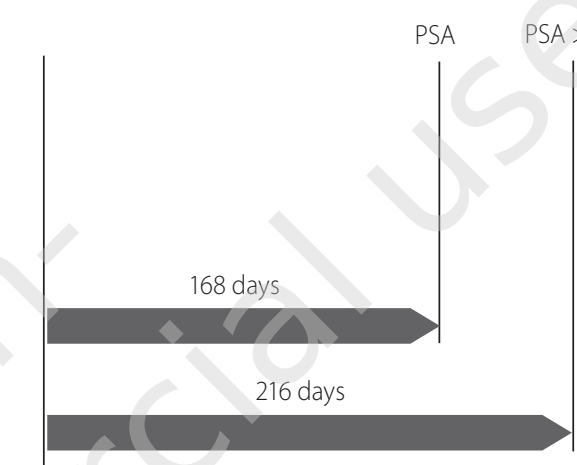

490 days

TABLE 3.

Impact of different factors on an earlier start of the diagnostic and therapeutic process.

\begin{tabular}{|c|c|c|c|c|c|c|}
\hline & \multicolumn{6}{|c|}{ Waiting time (median, days) } \\
\hline Prognostic factors & $\begin{array}{l}\text { from PSA } \\
>4 \mathrm{ng} / \mathrm{ml} \\
\text { to biopsy }\end{array}$ & $p$ & $\begin{array}{c}\text { from histopathological } \\
\text { diagnosis to the start of } \\
\text { treatment }\end{array}$ & $p$ & $\begin{array}{l}\text { from the onset of symptoms } \\
\text { to the start of treatment }\end{array}$ & $p$ \\
\hline \multicolumn{2}{|c|}{ Baseline PSA level (ng/ml) } & \multirow{4}{*}{0.39} & & \multirow{4}{*}{0.36} & & \multirow{4}{*}{0.003} \\
\hline$<10$ & 65 & & 72 & & 2267 & \\
\hline $10-20$ & 70 & & 52 & & 457 & \\
\hline$>20$ & 41 & & 69 & & 226 & \\
\hline \multicolumn{2}{|l|}{ TNM stage } & \multirow{3}{*}{0.30} & & \multirow{3}{*}{0.22} & & \multirow{3}{*}{0.39} \\
\hline $\mathrm{T} 1-2$ & 53 & & 63 & & 644 & \\
\hline T3-4 & 74 & & 72 & & 387 & \\
\hline \multicolumn{2}{|c|}{ Risk of progression } & \multirow{5}{*}{0.60} & & \multirow{5}{*}{0.17} & & \multirow{5}{*}{0.60} \\
\hline low & 92 & & 79 & & 2913 & \\
\hline intermediate & 59 & & 53 & & 592 & \\
\hline high & 50 & & 68 & & 398 & \\
\hline very high & 112 & & 80 & & 512 & \\
\hline \multicolumn{2}{|l|}{ Age (years) } & \multirow{3}{*}{0.10} & & \multirow{3}{*}{0.06} & & \multirow{3}{*}{0.89} \\
\hline$\leq 60$ & 26 & & 101 & & 523 & \\
\hline$>60$ & 67 & & 61 & & 490 & \\
\hline$\leq 70$ & 51 & \multirow{2}{*}{0.42} & 64 & \multirow{2}{*}{0.61} & 441 & \multirow{2}{*}{0.47} \\
\hline$>70$ & 69 & & 69 & & 594 & \\
\hline \multicolumn{2}{|c|}{ Place of residence } & \multirow{3}{*}{0.63} & & \multirow{3}{*}{0.06} & & \multirow{3}{*}{0.08} \\
\hline Olsztyn & 90 & & 47 & & 761 & \\
\hline $\begin{array}{l}\text { outside of } \\
\text { Olsztyn }\end{array}$ & 58 & & 70 & & 375 & \\
\hline
\end{tabular}


An analysis was conducted in order to determine which clinical factors might have an impact on an earlier initiation of diagnostics and treatment. PSA concentration levels ( $<10$ vs. $10-20$ vs. $>20 \mathrm{ng} / \mathrm{ml}$ ) were not found to be of significance with respect to the speed of scheduling prostate gland biopsy, even in those patients who complained about urinary problems. Additionally, PSA levels had no impact on the waiting time from receiving biopsy results to the initiation of anti-cancer treatment. A significant difference in time was demonstrated for the time from the onset of symptoms to the start of treatment between the group of patients whose baseline PSA level was lower than 10 $\mathrm{ng} / \mathrm{ml}$, and those subjects whose baseline PSA concentration was higher than $20 \mathrm{ng} / \mathrm{ml}(\mathrm{p}<0.05)$. No significant differences were found between the median times analyzed with respect to the TNM stage (T1-2 vs. T3-4) or with respect to the risk of progression (low vs. intermediate vs. high vs. very high). Taking into consideration the patients' age, no statistically significant differences were demonstrated for the median times under analysis between the different age brackets ( $\leq 60$ vs. $>60$ and $\leq$ 70 vs. $>70$ ). However, a positive correlation was demonstrated between the time from diagnosis to the initiation of treatment, and the distance from the patient's place of residence and the oncology center in Olsztyn $(r=0.24, p<0.05)$. Patients from outside of Olsztyn had to wait longer for treatment after receiving the diagnosis (70 vs. 47 days; a statistically non-significant difference, $p=0.06$ ) (tab. 3).

\section{DISCUSSION}

Prostate cancer ranks second in Poland (as of 2015) in terms of all cancer deaths in male patients (accounting for $8.8 \%$ of deaths due to malignancies in male patients) [2]. Despite the fact that the mortality rate in Poland is comparable to that in other European countries (standardized mortality ratio is ca. 23/100 thousand inhabitants), the relative 5 -year survival with the diagnosis of prostate cancer is lower than the European average [1, 2]. Waiting times for diagnosis and anti-cancer therapy might have an impact on the poorer treatment outcomes in Poland. The course of prostate cancer development is rarely aggressive, and it is not always accompanied by the characteristic urinary symptoms. Early diagnosis and initiation of treatment at a low clinical advancement stage may improve survival rates. Different authors demonstrated a link between prolonged waiting time for diagnosis and treatment, and poorer treatment outcomes in cancer patients. However, those studies involved tumors with different locations than prostate cancer, including head and neck tumors, breast cancer, lung cancer, cervical cancer or brain tumors. Chen et al. [18] indicated that in the case of head and neck tumors, delaying the time to radiotherapy by one month increases the risk of local recurrence by $19 \%$, and reduces the patients' overall survival, while in the case of breast cancer, it increases the risk of recurrence by $11 \%$. Similarly, van Harten et al. [19] pointed out that a prolonged waiting time for treatment, measured from the moment of receiving the histological diagnosis of a head and neck tumor, constitutes a significant negative prognostic factor, with a 3-month-long waiting period reducing the 5-year survival rate by $18 \%$ as compared to those patients whose therapy started immediately after the histological diagnosis. A clear link was also demonstrated between an extended waiting time for treatment, measured from the onset of symptoms, and poorer survival rates in breast cancer patients [20-22]. A longer wait for radiotherapy reduces local control in breast cancer, and shortens disease-free survival as well as overall survival [22], even though other others failed to confirm those findings [23, 24]. A meta-analysis [21] involving over 100 thousand patients demonstrated a link between a longer waiting time for treatment after the onset of symptoms, and reduced survival rates in breast cancer patients, while a longer duration of symptoms was correlated with diagnosing the disease at a more advanced stage. Results of a multi-factorial analysis indicated a negative impact of delayed radical radiotherapy on the survival of cervical cancer patients [25]. It appears that tumors with a fast growth dynamics and high metastatic potential should be diagnosed and treated as early as possible, even within several days from the onset of the first symptoms (e.g. small cell lung cancer). On the other hand, tumors whose growth dynamics is smaller and whose metastatic potential is low may be diagnosed at a slower pace, and their treatment may be delayed by several weeks or months. The latter group most probably includes prostate cancer in older men.

The present analysis demonstrated that the waiting time from prostate cancer suspicion to treatment is quite long. For patients with urinary problems, it took 24 weeks. Before the first PSA test was performed, 10 weeks would pass by from the finding of PSA $>4 \mathrm{ng} / \mathrm{ml}$ to prostate gland biopsy, and they had to wait for as long as 16 months for the initiation of anti-cancer therapy. Taking into consideration of all the study subjects, the median time from the finding of PSA $>4 \mathrm{ng} / \mathrm{ml}$ to prostate gland biopsy was nearly 9 weeks, which may not be a particularly long period of time, but the time from the histological diagnosis of prostate cancer to the start of treatment, which amounted to an additional 9 weeks, does seem relatively long. In a study conducted by Stevens et al., the median waiting time from prostate cancer suspicion to histopathological diagnosis was shorter than in our study ( 7.6 weeks) [26]. Generally speaking, the waiting time from the diagnosis of prostate cancer to radical radiotherapy is long and amounts to 
18 weeks $[26,27]$, while in the present analysis it was estimated as 24.1 weeks. The waiting time for hormone therapy was significantly shorter (7.6 weeks). Analyses indicate considerable differences in the waiting times for anti-cancer treatment depending on the tumor location, with the longest median waiting time applying to prostate cancer patients, and the shortest to those suffering from colorectal, lung and brain tumors [28, 29, own research, not published].

In a number of countries (e.g. England, Norway, Denmark, and the (zech Republic), there are guidelines and regulations determining the patients' waiting times for treatment. In England, the maximum statutory waiting time from the diagnosis of cancer to the start of treatment may not exceed 31 days. Similarly, in Denmark, the first oncological consultation must be carried out within 2 weeks from referral (referrals for specialist consultations are delivered via e-mail, and patients are invited to an appointment), and anti-cancer treatment must be initiated not later than within the following 2 weeks. In Poland, the fast-track oncological diagnostics and treatment reform, introduced on 1 January 2015, provided for specific time frames, within which the individual diagnostic steps were to be taken, followed by anti-cancer treatment (a maximum of 2 weeks from the completion of in-depth diagnostics and a tumor board meeting). In reality, however, the waiting times are much longer, with the median time from suspicion to treatment (of a tumor with a different location than prostate cancer) amounting to 11 weeks [own research, not published]. The present analysis demonstrated that with respect to prostate cancer, 70 weeks pass by from the onset of symptoms to the initiation of treatment over 22 weeks pass by from the finding of elevated PSA levels to the start of treatment, and it takes 9 weeks to start treatment from the histological confirmation of the disease. A similar study carried out in Canada indicated that prostate cancer patients, as compared with patients suffering from other malignancies, wait longer for treatment, and for radiotherapy in particular [30].
The present analysis demonstrated that the presence of symptoms suggestive of prostate cancer did not speed up diagnostics or treatment. PSA levels had no impact on how fast prostate gland biopsy was scheduled either, or on how fast therapy was initiated, with the exception of the group of males with urinary problems and PSA $>20 \mathrm{ng} / \mathrm{ml}$. TNM staging also appeared not to have any significant influence on the waiting times. On the other hand, the study indicated that patients who lived closer to the oncology center in question received treatment faster than those who came from outside of Olsztyn. The patients' age had no impact on the waiting time for diagnosis and treatment. Similarly, in the above mentioned study carried out by Stevens et al. [26], PSA levels, patient age, and TNM stages were not correlated with the duration of time from suspicion to diagnosis of prostate cancer, while the time from suspicion of prostate cancer to radiotherapy was significantly correlated with the patients' age and with the $T$ category. A study conducted in the UK demonstrated that from amongst a number of factors, it was only the patients' social status that had a significant impact on the overall waiting time for therapy [31]. The present study, on the other hand, points to the place of residence as the only significant variable.

\section{CONCLUSIONS}

Treatment outcomes in prostate cancer may be affected by the waiting time for diagnosis and initiation of treatment. In Poland, the time that passes by from prostate cancer suspicion until treatment is quite long, and the presence of symptoms indicative of prostate cancer does not accelerate the diagnostic and therapeutic process. A positive correlation has been demonstrated between the time from diagnosis to treatment, and the distance from the patient's place of residence to the oncology center involved in the study.

\section{References}

1. Stewart BW, Wild CP. World Cancer Report 2014. International Agency for Research on Cancer. World Health Organization 2014.

2. [online: http://onkologia.org.pl].

3. Rao AR, Motiwala HG, Karim O. The discovery of prostate-specific antigen. BJU Int 2008; 101: 5-10.

4. Sandhu GS, Andriole GL. Overdiagnosis of prostate cancer. J Natl Cancer Inst Monogr 2012: 146-151.

5. Rove KO, Crawford ED. Randomized controlled screening trials for prostate cancer using prostate-specific antigen: a tale of contrasts. World J Urol 2012; 30: 137-142.

6. van den Bergh RCN, Albertse PC, Bangma CH et al. Timing of curative treatment for prostate cancer: A systematic review. Eur Urol 2013; 64: 204$-215$.

7. Freedland SJ, Kane CJ, Amling CL et al. Delay of radical prostatectomy and risk of biochemical progression in men with low risk prostate cancer. J Urol 2006; 175: 1298-1303.

8. Nam RK, Jewett MA, Krahn MD et al. Delay in surgical therapy for clinically localized prostate cancer and biochemical recurrence after radical prostatectomy. Can J Urol 2003; 10: 1891-1898. 
9. Graefen M, Walz J, Chun KHF et al. Reasonable delay of surgical treatment in men with localized prostate cancer - impact on prognosis? Eur Urol 2005; 47: 756-760.

10. Siemens DR, Schulze KM, Mackillop WJ et al. A population-based study of the waiting times for prostatectomy in Ontario. Can J Urol 2005; 12 : 2568-2574.

11. Nakayama H, Kanemoto A, Kikuchi K et al. Delayed radiotherapy for patients with localized prostate cancer: validation by propensity score matching. Anticancer Res 2013; 33: 1629-1633.

12. Nguyen $\mathrm{PL}$, Whittington $\mathrm{R}$, Koo $\mathrm{S}$ et al. The impact of a delay in initiating radiation therapy on prostate-specific antigen outcome for patients with clinically localized prostate carcinoma. Cancer 2005; 103: 2053-2059.

13. Andrews SF, Horwitz EM, Feigenberg SJ et al. Does a delay in external beam radiation therapy after tissue diagnosis affect outcome for men with prostate carcinoma? Cancer 2005; 104: 299-304.

14. Saad F, Finelli A, Dranitsaris G et al. Does prolonging the time to prostate cancer surgery impact long-term cancer control: a systematic review of the literature. Can J Urol 2006; 13(Suppl 3): 16-24.

15. Fitch MI, Gray RE, McGowan T et al. Travelling for radiation cancer treatment: Patient perspectives. Psycho-Oncol 2003; 12: 664-674.

16. Steineck G, Helgesen F, Adolfsson J et al. Quality of life after radical prostatectomy or watchful waiting. NEJM 2002; 347: 790-796.

17. Saegrov S, Halding AG. What is it like living with the diagnosis of cancer? Eur J Cancer Care 2004; 13: 145-153.

18. Chen Z, King W, Pearcey R et al. The relationship between waiting time for radiotherapy and clinical outcomes: a systematic review of the literature. Radiother Oncol 2008; 87: 3-16.

19. van Harten MC, Hoebers FJP, Kross KW et al. Determinants of treatment waiting times for head and neck cancer in the Netherlands and their relation to survival. Oral Oncol 2015; 51:272-278.

20. Montella M, Crispo A, Botti G et al. An assessment of delays in obtaining definitive breast cancer treatment in Southern Italy. Breast Cancer Res Treat 2001; 66: 209-215.

21. Richards MA, Westcombe AM, Love SB et al. Influence of delay on survival in patients with breast cancer: a systematic review. Lancet 1999; 353 : 1119-1126.

22. Buchholz TA, Austin-Seymour MM, Moe RE et al. Effect of delay in radiation in combined modality treatment of breast cancer. Int J Radiat Oncol Biol Phys 1993; 26: 23-35.

23. Nixon AJ, Recht A, Neuberg $D$ et al. The relation between the surgery-radiotherapy interval and treatment outcome in patients treated with breast-conserving surgery and radiation therapy without systemic therapy. Int J Radiat Oncol Biol Phys 1994; 30: 17-21.

24. Froud PJ, Mates D, Jackson JS et al. Effect of time interval between breast-conserving surgery and radiation therapy on ipsilateral breast recurrence. Int J Radiat Oncol Biol Phys 2000; 46: 363-372.

25. Choan E, Dahrouge S, Samant R et al. Radical radiotherapy for cervix cancer: The effect of waiting time on outcome. Int J Radiat Oncol Biol Phys 2005; 61: 1071-1077.

26. Stevens C, Bondy SJ, Loblaw DA. Wait times in prostate cancer diagnosis and radiation treatment. Can Urol Assoc J 2010; 4: $243-248$.

27. Johnston GM, MacGarvie VL, Elliott D et al. Radiotherapy wait times for patients with diagnosis of invasive cancer, 1992-2000. Clin Invest Med 2004; 27: 142-156.

28. Bardell T, Belliveau P, Kong W et al. Waiting times for cancer surgery in Ontario: 1984-2000. Clin Oncol 2006; 18: 401-409.

29. Osowiecka K, Rucińska M, Nawrocki S. Have actual waiting times been reduced by introducing the DILO reform for cancer patients in Poland? Nowotwory. J Oncol 2017; 67: 168-173.

30. Tran K, Sandoval C, Rahal R et al. Wait times for prostate cancer treatment and patient perceptions of care in Canada: a mixed-methods report. Curr Oncol 2015; 22: 361-364.

31. Neal RD, Allgar VL. Sociodemographic factors and delays in the diagnosis of six cancers: analysis of data from the "National Survey of NHS Patients: Cancer." Br J Cancer 2005; 92: 1971-1975.

Authors' contributions: Monika Rucińska: 20\%; Karolina Osowiecka: 20\%; Szymon Gałka: 15\%; Radosław Środa: 15\%; Piotr Wojciechowski: 15\%; Anna Sugajska: 15\% Conflict of interests: None. Financial support: 